\title{
Piyasada Satılan Bazı Poşet Çayların Toplam Fenolik, Flavonoid Bileşen İçeriği ve Antioksidan Aktivitesinin Belirlenmesi
}

\author{
Zeynep Kübra MENEKŞE ${ }^{1}$, Burcu MARANGOZ², Sibel KAHRAMAN*
}

\section{Öz}

$\mathrm{Bu}$ çalışmada marketlerde satılmakta olan üç farklı markaya ait poşet bitki ve meyve çaylarının toplam fenolik, toplam flavonoid bileşen içerikleri ve antioksidan kapasiteleri belirlenmiştir. Poşet çayların antioksidan aktivitelerinin tayininde, \% DPPH (2,2-Difenil-1-pikrilhidrazil) radikal giderme aktivitesi ve indirgeme gücü metotları kullanılmıştır. Poşet çayların toplam fenolik ve toplam flavonoid değerleri sırasıyla 6.46-83.87 (mg GAE/g) ve 3.54 - 35.16 mg CE/g olarak belirlenmiştir. Analizi yapılan her üç markada \% DPPH radikal giderme aktivitesi \% 63-95 arasında değişkenlik göstermiştir. İndirgeyici güç değeri ise 0.267-0.456 arasında bulunmuştur.

Anahtar Kelimeler: Antioksidan, Fenolik, Flavonoid, Poşet Çay.

\section{Determination of Total Phenolic, Flavonoid Content and Antioxidant Activity of Some Tea Bags in Markets}

\begin{abstract}
Total phenolic, flavonoid and antioxidant capacity of some commercially bagged herbal and fruit teas which belong to 3 different labels in Turkey's markets were measured. \% DPPH radical scavenging activity and reducing power were used for determining antioxidant activity. Total phenolic and flavonoid content of bagged teas were found as $6.46-83.87$ (mg GAE/g) and $3.54-35.16 \mathrm{mg} \mathrm{CE} / \mathrm{g}$ respectively. For all bagged herbal and fruit teas DPPH radical scavenging activity and reducing power were found as $63-95 \%$ and $0.267-0.456$ respectively.
\end{abstract}

Keywords: Antioxidant, Flavonoid, Phenolics, Tea Bag

\footnotetext{
${ }^{1}$ Gebze Teknik Üniversitesi, Kimya Mühendisliği, Mühendislik Fakültesi, Kocaeli, Türkiye, zkmenekse@ztu.edu.tr ${ }^{2}$ İstanbul Aydın Üniversitesi, Gıda Mühendisliği, Mühendislik Fakültesi, İstanbul, Türkiye, mrngzburcu@gmail.com ${ }^{3}$ İstanbul Aydın Üniversitesi, Gastronomi ve Mutfak Sanatları, Güzel Sanatlar Fakültesi, İstanbul, Türkiye, sibelkahraman@aydin.edu.tr
} 


\section{Giriş}

Çay dünyada sudan sonra en fazla tüketilen ikinci içecektir (Piljac-Žegarac ve ark., 2010). Son yıllarda sağlıklı yaşam arayışı ve beslenmeye artan ilgi nedeniyle bitkisel çayların kullanımı yaygınlaşmış ve popülaritesi giderek artmıştır. Bitkisel çaylar, antioksidan özellik taşıyan ve bunun yanı sıra sağlık üzerine olumlu etkileri bulunan biyoaktif bileşenler içermektedir. Kateşinler, flavonoller, flavonlar ve fenolik asitler gibi polifenolik bileşikler içeren çaylar antikarsinojenik, antimutajenik ve kardiyovasküler hastalıklara karşı koruyucu özelliklere sahip olduğu belirtilmektedir (Shahidi ve Naczk, 1995). Antioksidanlar çeşitli mekanizmalarla açığa çıkan serbest radikalleri gidererek bu radikallerin DNA, proteinler ve lipidler gibi hücre bileşenlerinde yol açabileceği hücre hasarlarını engellemektedirler. Bu hücre hasarları yaşlanma, enflamasyon, arterosklerozis, iskemik yaralanmalar ve kansere yol açabilmektedir (Kähkönen ve ark., 1999).

Son yıllarda tüketicilerin bilinçlenmesi, sentetik gıdalara karşı tepki oluşması ve kullanım rahatlığı gibi etkenlerle fincan poşetleri(ipli) şeklindeki bitki-meyve çaylarının günlük yaşantıdaki kullanımını yaygınlaşmıştır. Bu nedenle tüm dünyada gittikçe çeşitlenen ve üretim kapasitesi yüksek bir sektör ortaya çıkmıştır (Akgün ve Ünver, 2001). Bitkisel çay üretiminde, sayısız bitki türü tek başına ya da birkaç bitki bir arada kullanılabildiğinden, ürünlerin duyusal özellikleri ve sağlık üzerine etkileri son derece farklıdır. Poşet çaylar günümüzde sıklıkla tüketilmelerine rağmen marketlerde satılan poşet çayların fenolik bileşen içerikleri ve antioksidan aktiviteleri ve bunlar arasındaki korelasyonla ilgili çok fazla araştırma bulunmamaktadır.

Bu çalışmanın amacı Türkiye'de marketlerde satılan farklı markalara ait poşet çayların toplam fenolik, flavonoid bileşen içeriğinin belirlenmesi ve antioksidan aktivitesinin incelenmesidir. Bu amaçla marketlerde satılan bazı poşet bitki ve meyve çaylarının toplam fenolik bileşen, toplam flavonoid içeriği belirlenmiştir. Poşet çayların antioksidan aktivitesi ise DPPH radikal inhibisyonu ve indirgeme gücü yöntemi ile tayin edilmiştir. Çayların toplam fenolik, flavonoid bileşen içerikleri kıyaslanmış ve antioksidan aktiviteleri arasındaki korelasyon hesaplanmıştır. Türkiye'de marketlerde satılan poşet çayların antioksidan profiline dair bu kadar geniş kapsamlı bir çalışma mevcut değildir.

\section{Materyal ve Metot}

Türkiye'deki market zincirlerinden 3 farklı markaya ait poşet çay numuneleri temin edilmiştir. Bu markalar Marka 1, Marka 2, Marka 3 olarak adlandırılmıştır. Markaların poşet çay içerikleri Tablo 1,2 ve 3'de görülmektedir. 
Tablo 1. Marka 1 poşet çay örneklerinin içindekiler

\begin{tabular}{|c|c|}
\hline Bitki ve meyve çayları & İçindekiler \\
\hline Adaçayı & Adaçay 1 \\
\hline Meyve çayı 1 (M1MÇ1) & $\begin{array}{l}\text { Limon otu, melisa yaprağı, kıvırcık nane, mandalina, portakal kabuğu, limon } \\
\text { kabuğu, biberiye. }\end{array}$ \\
\hline Meyve çayı 2 (M1MÇ2) & $\begin{array}{l}\text { Karabaş otu, zeytin yaprağı, adaçayı, biberiye, dut yaprağı, anason, lavanta, } \\
\text { üzüm suyu tozu }\end{array}$ \\
\hline Böğürtlen & $\begin{array}{l}\text { Elma, bamya çiçeği, kuşburnu, böğürtlen yapră̆ı, portakal meyve kabuğu, } \\
\text { stevya, mürver, tarçın, böğürtlen }\end{array}$ \\
\hline Elma & Elma, bamya çiçeği, tarçın, hindiba kökü \\
\hline Bitki çayı 1 (M1BÇ1) & $\begin{array}{l}\text { Sinameki yaprağı, rezene, böğürtlen yaprağı, mate yaprăğ , biberiye, funda } \\
\text { çiçeği, kiraz meyve sapı, maydanoz, stevya, açai suyu konsantresi }\end{array}$ \\
\hline Bitki çayı 2 (M1BÇ2) & $\begin{array}{l}\text { Sinameki yaprağı, rezene, böğürtlen yaprağı, mate yaprağı, biberiye, funda } \\
\text { çiçeği, kiraz meyve sapı, maydanoz, zencefil, şeftali }\end{array}$ \\
\hline Bitki çayı 3 (M1BÇ3) & $\begin{array}{l}\text { Sinameki yaprağı, rezene, mate yaprağı, funda çiçeği, biberiye, böğürtlen } \\
\text { yaprağı, hindiba, kiraz meyve sapı, maydanoz, stevya, açai suyu konsantresi }\end{array}$ \\
\hline Bitki çayı 4 (M1BÇ4) & Zahter, biberiye, elma, anason, nar kabuğu, meyan kökü \\
\hline Ihlamur & Ihlamur, dut yaprağı, roybos, tarçın \\
\hline Kuşburnu & Kuşburnu, bamya çiçeği \\
\hline Papatya & Mayıs papatyası \\
\hline Rezene & Rezene, tıbbi nane \\
\hline Yeşil çay & Yeşil çay \\
\hline Zencefil Limon & Zencefil, limon otu, portakal kabuğu, meyankökü, limon kabuğu \\
\hline
\end{tabular}


Tablo 2. Marka 2 poşet çay örneklerinin içindekiler

\begin{tabular}{|c|c|}
\hline Bitki ve meyve çayları & Içcindekiler \\
\hline Adaçayı & Adaçayı yaprakları \\
\hline Böğürtlen & $\begin{array}{l}\text { Elma, bamya çiçeği, tarçın, böğürtlen yaprakları, mürver ağacı meyvesi, portakal } \\
\text { kabuğu rendesi, kuşburnu }\end{array}$ \\
\hline Elma & Elma, bamya çiçeği, tarçın, böğürtlen yaprakları \\
\hline Ekinezya & Ekinezya, tarçın, limon kabuğu, melisa yaprağı, nane yaprağı, karanfil çiçeği \\
\hline Bitki çayı 1 (M2BÇ1) & $\begin{array}{l}\text { Sinameki yaprağı, biberiye yaprağı, adaçayı yaprağı, sarı kantaron, anason meyvesi, } \\
\text { rezene meyvesi, kuşburnu meyvesi, 1sırgan yaprağı, ardıç ağacı meyvesi, civan } \\
\text { perçemi, funda yaprağı, fasulye kabuğu, kiraz sapı, kayısı parçacıkları }\end{array}$ \\
\hline Ihlamur & Ihlamur \\
\hline Kuşburnu & Kuşburnu, bamya çiçeği \\
\hline Meyve çayı 1 (M2MÇ1) & $\begin{array}{l}\text { Elma meyvesi parçacıkları, kuşburnu meyvesi, bamya çiçeği, üzüm çekirdekleri } \\
\text { tohumu, nar meyvesi kabuğu, portakal kabuğu, böğurtlen yaprakları, çilek meyve } \\
\text { parçacıkları }\end{array}$ \\
\hline Bitki çayı 2 (M2BÇ2) & $\begin{array}{l}\text { Tarçın kabuğu, siyah çay, zencefil, böğ̈̈rtlen yaprakları, hindiba kökü, karanfil } \\
\text { çiçek tohumu, kakule meyvesi, karabiber meyvesi, stevya yaprakları, meyan kökü }\end{array}$ \\
\hline Papatya & Papatya çiçekleri \\
\hline Rezene & Rezene \\
\hline Yeşil çay & Yeşil çay \\
\hline
\end{tabular}


Tablo 3. Marka 3 poşet çay örneklerinin içindekiler

\begin{tabular}{|c|c|}
\hline Bitki ve meyve çayları & İçindekiler \\
\hline Adaçayı & Adaçayı yaprakları \\
\hline Böğürtlen & $\begin{array}{l}\text { Bamya çiçeği, elma, kuşburnu, böğürtlen yaprağı, portakal kabuğu, mürver } \\
\text { meyvesi, tarçın, böğürtlen }\end{array}$ \\
\hline Elma & Elma, bamya çiçeği, böğürtlen yaprağ 1 , limon kabuğu, tarçın \\
\hline Ekinezya & $\begin{array}{l}\text { Ekinezya, böğürtlen yaprağı, , hlamur, roybos, karanfil, elma, adaçayı, limon } \\
\text { kabuğu, portakal kabuğu, zerdeçal, karabiber, tarçın }\end{array}$ \\
\hline Ihlamur & Ihlamur, karanfil, roybos, tarçın \\
\hline Kuşburnu & Kuşburnu, bamya çiçeği \\
\hline Rezene & Rezene, anason \\
\hline Meyve çayı 1 (M3MÇ1) & Bamya çiçeği, kuşburnu, elma, mürver meyvesi, portakal kabuğu, yaban mersini \\
\hline Yeşil çay & Yeşil Çay, böğürtlen yaprağı, Ginkgo yaprağ \\
\hline
\end{tabular}

\subsection{Poşet Çayların Hazırlanması}

Poşet çay numunelerine $(2.1 \mathrm{~g}) 150 \mathrm{~mL} 85^{\circ} \mathrm{C}^{\prime}$ ye 1 sıtılmış su ilave edilmiştir. 3 dakika bekletildikten sonra poşet çıkarılmış ve bu şekilde elde edilen çay infüzyonları analizlerde kullanılmıştır. Tüm poşet çay infüzyonları aynı içme suyu ile hazırlanmıştır.

\subsection{Toplam Fenolik Bileşen Tayini}

Hazırlanan poşet çay infüzyonlarından 0.1 'er $\mathrm{mL}$ alınarak üzerlerine toplam hacim $4.5 \mathrm{~mL}$ olacak şekilde destile su ilave edilmiştir. Destile su ile 1:2 oranında seyreltilen Folin-Ciocalteau ayıracından $0.1 \mathrm{~mL}$ ve ardından \%2'lik $\mathrm{Na}_{2} \mathrm{CO}_{3}$ çözeltisinden $0.3 \mathrm{~mL}$ ilave edilmiştir. Tüpler vorteks ile karıştırılıp, karışımlar 2 saat karanlıkta ve oda sıcaklığında bekletilmiştir. Kör çözelti ise $0.1 \mathrm{~mL}$ çay numunesi yerine distile su konularak hazırlanmıştır. 2 saatin sonunda tüplerde oluşan mavi-yeşil renkteki çözeltilerin absorbansı 760 nm'de köre karşı belirlenmiştir (Singleton ve Rossi, 1965).

Örneklerin toplam fenolik madde içeriği, gallik asit standardı kullanılarak oluşturulan standart kalibrasyon eğrisi yardımıyla mg gallik asit eşdeğeri (GAE)/g cinsinden ifade edilmiştir. 


\subsection{Toplam Flavonoid Bileșen Tayini}

Poşet çay örneklerinin toplam flavonoid bileşen içeriği Zhishen ve ark., (1999) metoduna göre belirlenmiştir. Poşet çay numunelerinden $0.25 \mathrm{~mL}$ tüplere alınarak üzerlerine $1.25 \mathrm{~mL}$ destile su ilave edilmiştir. Tüplere \% 5'lik $\mathrm{NaNO}_{2}$ çözeltisinden $75 \mu \mathrm{L}$ ilave edildikten sonra karıştırılmış ve 6 dakika boyunca bekletilmiştir. $150 \mu \mathrm{L} \% 10$ 'luk $\mathrm{AlCl}_{3}$ çözeltisi ilave edilerek 5 dakika bekletilmiştir. Daha sonra, her bir tüpe $1 \mathrm{M}^{\prime} l 1 \mathrm{k} \mathrm{NaOH}$ çözeltisinden $0.5 \mathrm{~mL}$ konulmuştur. Son olarak da tüplere $275 \mu \mathrm{L}$ distile su ilave edilmiştir. Kör çözelti, $0.25 \mathrm{~mL}$ çay numunesi yerine destile su konularak hazırlanmıştır. Örneklerin absorbansı 510 nm’de köre karşı ölçülmüştür.

Örneklerin toplam flavonoid bileşen içeriği, kateşin standardı kullanılarak oluşturulan standart kalibrasyon eğrisinden yararlanılarak mg kateşin(CE) eşdeğeri/g olarak hesaplanmıştır.

\subsection{Antioksidan Aktivite Tayini}

\subsubsection{DPPH Radikali İnhibisyonu Tayini}

Poşet çay örneklerinin antioksidan aktivitesi, 2,2-Difenil-1-pikrilhidrazil radikali kullanılarak belirlenmiştir (Brand-Williams ve ark., 1995). DPPH çözeltisi dayanıksız olduğundan günlük olarak 20 mg/L konsantrasyonun da metanol de çözülerek hazırlanmış ve işlem sırasında ışıktan korunarak muhafaza edilmiştir. DPPH radikalinden $1.5 \mathrm{~mL}$ alınmış, çay numunelerinden $0.75 \mathrm{~mL}$ hacminde üzerine eklenerek 517 nm'de 0. ve 30. dakikadaki absorbans değerleri okunmuştur. \% DPPH radikali inhibisyonu aşağıdaki formüle göre hesaplanmıştır.

0.dakikadaki absorbans değeri $=\left(\mathrm{A}_{0}\right) ;$ 30.dakikadaki absorbans değeri $=(\mathrm{A})$

$\%$ İnhibisyon $\left.=\left(\mathrm{A}_{0}-\mathrm{A}\right) / \mathrm{A}_{0}\right) \times 100$

Standart olarak butillenmiş hidroksi anizol (BHA) kullanılmıştır.

\subsection{2. İndirgeme Gücü Antioksidan Kapasitesi Tayini}

Poşet çay örneklerinin indirgeme gücü kapasitesi Oyaizu (1986) metoduna göre tayin edilmiştir. $1 \mathrm{~mL}$ poşet çay numunelerinden tüplere alınarak üzerlerine $2.5 \mathrm{~mL} 0.2 \mathrm{M}^{\prime}$ 'lık fosfat tamponu (pH: 6.6) ve $2.5 \mathrm{~mL} \% 1$ 'lik $\mathrm{K}_{3} \mathrm{Fe}(\mathrm{CN})_{6}$ çözeltisinden ilave edilmiştir. Hazırlanan bu karışımlar $50^{\circ} \mathrm{C}$ 'deki su banyosunda 30 dakika süresince inkübe edilmiştir. $2.5 \mathrm{~mL} \% 10$ 'luk trikloro asetik asit(TCA) çözeltisi eklendikten sonra 10 dakika 3000 rpm'de santrifüjlenmiştir. Santrifüj sonrası üst fazdan $5 \mathrm{~mL}$ alınarak $5 \mathrm{~mL}$ destile su ile seyreltilmiştir. Daha sonra $1 \mathrm{~mL} \% 0.1^{\prime}$ lik $\mathrm{FeCl}_{3}$ çözeltisi ile karıştırılarak, örneklerin absorbansı 700 nm'de kör çözeltiye karşı belirlenmiştir. Kör 
çözelti çay örnekleri yerine su kullanılarak aynı şekilde hazırlanmıştır. Standart olarak BHA çözeltisi kullanılmıştır.

\section{5. İstatistiksel Analizler}

Tüm deneyler iki kere tekrarlanmıştır. İstatistiksel analizler ve korelasyon ilişkisi IBM Statistics 19 programı kullanılarak yapılmıştır. Ortalamalar arasındaki korelasyon katsayıları Pearson ve Spearson korelasyon testi uygulanarak belirlenmiştir.

\section{Bulgular ve Tartışma}

\subsection{Toplam Fenolik Bileşen Tayini}

Marketlerde satılan poşet bitki/meyve çaylarından bazılarının toplam fenolik bileşen miktarları Tablo 4'te görülmektedir. Marketlerde satılan analizi yapılan poşet çayların toplam fenolik bileşen içerikleri $6.46 \pm 0.29-83.87 \pm 0.8 \mathrm{mg} \mathrm{GAE} / \mathrm{g}$ arasında değişiklik gösterdi. Buna göre en yüksek toplam fenolik bileşen değeri her üç markada da adaçayında bulunmuştur. Üç markanın adaçaylarında toplam fenolik bileşen içeriği marka 1,2 ve 3 için sırasıyla $73.71 \pm 0.63,83.87 \pm 0.80,75.83 \pm 2.1$ mg GAE/g olarak belirlenmiştir. Miliauskas ve ark., (2004) tarafından yapılan bir çalışmada farklı adaçayı türleri için toplam fenolik bileşen içeriği 9.7- $24.0 \mathrm{GAE} \mathrm{mg} / \mathrm{g}$ bitki ekstraktı olarak bulunmuştur.

En düşük toplam fenolik bileşen değeri ise papatya, ıhlamur ve rezene çayları için bulunmuştur. Toplam fenolik bileşen içeriği papatya poşet çayları için $6.46 \pm 0.29-10.89 \pm 0.17 \mathrm{mg} \mathrm{GAE} / \mathrm{g}$ aralığında bulunmuştur. Literatürde papatya için toplam fenolik bileşen değeri mevsimsel değişimlere göre 2.81-3.57 mg GAE/100 mg kuru ağırlık olarak bildirilmiştir (Siatka ve Kasparova, 2010). Cavlak ve Yağmur (2016), bitki çayları ile ilgili yaptığı bir çalışmada en yüksek fenolik bileşen içeriği yeşil çay ve adaçayı için bulunmuş, en düşük fenolik bileşen içeriği ise rezene ve papatya çayları için bulunmuştur. Bizim çalışmamızdaki toplam fenolik bileşen sıralaması bu çalışmayla örtüşmektedir. 
Tablo 4. Poşet çayların toplam fenolik bileşen içeriği

\begin{tabular}{|l|l|l|l|}
\hline \multirow{2}{*}{ Örnek Ad1 } & \multicolumn{3}{|c|}{ Konsantrasyon(mg GAE/g) } \\
\cline { 2 - 4 } & Marka 1 & Marka 2 & Marka 3 \\
\hline Adaçay1 & $73.71 \pm 0.63$ & $83.87 \pm 0.80$ & - \\
\hline M1MÇ1 & $63.86 \pm 0.84$ & - & $26.46 \pm 0.29$ \\
\hline Böğ̈urtlen & $18.27 \pm 1.59$ & $28.60 \pm 0.38$ & $22.23 \pm 0.46$ \\
\hline Elma & $13.60 \pm 0.46$ & $30.59 \pm 0.01$ & $33.69 \pm 2.53$ \\
\hline Ekinezya & - & $42.35 \pm 0.21$ & - \\
\hline M1MÇ2 & $24.70 \pm 0.06$ & - & - \\
\hline M1BÇ1 & $21.61 \pm 0.42$ & - & - \\
\hline M1BÇ2 & $24.64 \pm 0.08$ & - & - \\
\hline M1BÇ3 & $16.88 \pm 0.21$ & - & - \\
\hline M2BÇ1 & - & $20.45 \pm 0.72$ & - \\
\hline M1BÇ4 & $37.32 \pm 0.03$ & - & - \\
\hline Ihlamur & $7.02 \pm 0.92$ & $17.86 \pm 0.21$ & $33.21 \pm 0.17$ \\
\hline Kuşburnu & $28.18 \pm 0.21$ & $42.38 \pm 0.59$ & - \\
\hline M2MÇ1 & - & $37.65 \pm 0.88$ & - \\
\hline M2BÇ2 & - & $45.77 \pm 0.67$ & - \\
\hline Papatya & $6.46 \pm 0.29$ & $10.89 \pm 0.17$ & $13.72 \pm 3.58$ \\
\hline Rezene & $12.24 \pm 0.21$ & $17.86 \pm 0.21$ & $31.37 \pm 2.19$ \\
\hline M3MÇ1 & - & - & $34.43 \pm 2.15$ \\
\hline Yeşil çay & $41.93 \pm 0.21$ & $46.10 \pm 0.21$ & - \\
\hline Zencefil Limon & $11.04 \pm 0.38$ & - & \\
\hline Not-île & & \\
\hline
\end{tabular}

Not: - ile gösterilen sütunlardaki çay türü belirtilen markada üretilmemektedir. Bu nedenle analizi yapılamamıştır.

Adaçaylarının toplam fenolik bileşen içerikleri analizi yapılan diğer tüm çay örneklerinden yüksek bulunmuştur. Her üç markada da fenolik bileşen içeriği yüksek bulunan bir diğer çay örneği de yeşil çaydır. Bir karışım olan M1MÇ1 meyve çayında ise yeşil çaydan daha yüksek oranda fenolik bileşen içeriği belirlenmiştir. Bunun yanı sıra çeşitli bitki ve meyvelerin karıştırılmasıyla elde edilen bitki çaylarında fenolik bileşen içeriği daha düşük bulunmuştur. Karışım çaylar fenolik bileşen içeriğinde her zaman sinerjik bir etkiye sahip olmamaktadır.

Elma çaylarında ise değerler markalara göre oldukça değişkenlik göstermiştir. Bunun da sebebi elma çaylarının elmanın yanı sıra farkıı bileşenler içermesi ve markaya göre bu karışımların kompozisyonlarının birbirinden farklı olmasıdır.

Fenolik bileşenler en önemli doğal antioksidan kaynakları arasındadırlar. Yapılarında içerdikleri hidroksil grupları sayesinde işleme, depolama sırasında gıdaların lipid peroksidasyonu nedeniyle olan bozulmaları, radikal süpürme yeteneği sayesinde azalttıkları bilinir. Aynı zamanda insan vücudunda serbest radikaller nedeniyle meydana geldiği bilinen hastalıkların önlenmesinde de rol oynarlar (Şahin, 2013).

\subsection{Toplam Flavonoid İçeriği}

Marketlerde satılan poşet çayların toplam flavonoid içerikleri Tablo 5'de görülmektedir. Buna göre analizi yapılan poşet çayların toplam flavonoid içerikleri $3.54-35.16 \mathrm{mg} \mathrm{CE} / \mathrm{g}$ arasında 
değişmektedir. Şahin (2013), çeşitli meyve çayları ile ilgili yaptığı çalışmada meyve çaylarının toplam flavonoid içeriklerini 1.7-36.81 mg CE/g aralığında bildirmiştir. Toplam fenolik bileşen içerikleriyle uyumlu olarak, en yüksek flavonoid bileşen içeriğine adaçayı örneklerinde en düşük toplam flavonoid bileşen içeriğine ise papatya çaylarında rastlanmaktadır. Flavonoid bileşenler fenoliklerin alt sınıfları arasında yer almaktadır. Toplam fenolik ve flavonoid değerlerinin birbiriyle örtüşmesi çalışmamızda kullanılan çaylarda bulunan fenoliklerin önemli bir kısmının flavonoidlerden oluştuğu şeklinde yorumlanabilir. Bitki çaylarının hazırlanış biçimi ile flavonoid miktarı birbiriyle ilişkilidir (Cavlak ve Yağmur, 2016).

Tablo 5. Poşet çayların toplam flavonoid bileşen içeriği

\begin{tabular}{|c|c|c|c|}
\hline \multirow[b]{2}{*}{ Örnek Adı } & \multicolumn{3}{|c|}{ Konsantrasyon(mg CE/g) } \\
\hline & Marka 1 & Marka 2 & Marka 3 \\
\hline Adaçayı & $35.16 \pm 1.26$ & $23.13 \pm 1.14$ & $23.24 \pm 0.24$ \\
\hline M1MÇ1 & $23.23 \pm 0.43$ & - & - \\
\hline Böğürtlen & $9.04 \pm 0.16$ & $7.15 \pm 0.77$ & $10.25 \pm 0.16$ \\
\hline Elma & $7.03 \pm 0.28$ & $8.92 \pm 0.90$ & $8.64 \pm 0.47$ \\
\hline Ekinezya & - & $19.79 \pm 0.46$ & $18.04 \pm 0.16$ \\
\hline M1MÇ2 & $22.03 \pm 0.69$ & - & - \\
\hline M1BÇ1 & $15.41 \pm 0.84$ & - & - \\
\hline M1BÇ2 & $19.42 \pm 0.13$ & - & - \\
\hline M1BÇ3 & $12.25 \pm 2.02$ & - & - \\
\hline M2BÇ1 & - & $8.00 \pm 0.74$ & - \\
\hline M1BÇ4 & $16.76 \pm 0.79$ & - & - \\
\hline Ihlamur & $4.89 \pm 0.25$ & $5.32 \pm 0.24$ & - \\
\hline Kuşburnu & $12.05 \pm 0.19$ & $12.46 \pm 0.22$ & $16.15 \pm 0.16$ \\
\hline M2MÇ1 & - & $8.67 \pm 0.62$ & - \\
\hline M2BÇ2 & - & $13.47 \pm 1.41$ & - \\
\hline Papatya & $4.22 \pm 1.11$ & $3.54 \pm 0.30$ & - \\
\hline Rezene & $9.35 \pm 0.92$ & $6.15 \pm 0.46$ & $5.38 \pm 0.35$ \\
\hline M3MÇ1 & - & - & $10.71 \pm 0.25$ \\
\hline Yeşil çay & $20.94 \pm 0.35$ & $12.10 \pm 0.54$ & $13.97 \pm 0.06$ \\
\hline Zencefil Limon & $9.42 \pm 1.14$ & - & - \\
\hline
\end{tabular}

Not: - ile gösterilen sütunlardaki çay türü belirtilen markada üretilmemektedir. Bu nedenle analizi yapılamamıştır. 
Kuşburnunda bulunan polifenolik bileşenler antosiyaninler, fenolik asitler ve flavonollerdir (Pérez-Ramírez ve ark., 2011, Sáyago-Ayerdi ve ark., 2014). Bu bileşenlerin yüksek antioksidan özellikleri sebebiyle sağlık üzerine olumlu etkileri bulunmaktadır (Sáyago-Ayerdi ve ark., 2014).

Aynı çayın farklı markalarda farklı flavonoid içeriğine sahip olması bitki veya meyvenin farklı toprak ve iklim şartlarına maruz kalmasından kaynaklı flavonoid kompozisyonunda farklılıklar göstermesiyle açıklanabilir.

\subsection{Antioksidan Aktivite Tayini}

\subsubsection{DPPH Radikali İnhibisyonu}

1,1-difenil-2-pikrilhidrazil (DPPH) radikali 517 nm'de absorbans veren kararlı bir radikaldir ve antioksidanlar tarafından indirgenir. Bu indirgenme reaksiyonu kolaylıkla gerçekleştiğinden DPPH radikali inhibisyonu antioksidan aktivite tayininde sıkl1kla kullanılan bir metottur (Brand-Williams, 1995). Marka 1, 2 ve 3'ün \% DPPH radikali inhibisyonu sonuçları Şekil 1, 2, 3’te görülmektedir. Poşet çayların önemli oranda DPPH radikali inhibisyonu kapasitesine sahip olduğu bulunmuştur. Marka 1'in \% DPPH radikali inhibisyonu \% 63-93 arasında bulunmuştur. Buna göre en düşük değer \% 63 olarak kuşburnu çayında ölçülmüştür. En yüksek değer ise \% 93 olarak meyve çayı karışımı olan M1MÇ1 çayında bulunmuştur. Marka 2'nin \% DPPH radikal inhibisyon değerleri ise Marka 1'e göre daha yüksek olarak \% 80-95 aralığında bulunmuştur. En düşük değer \% 80 olarak M2BÇ2 için bulunurken en yüksek değer adaçayı, ıhlamur, yeşilçay ve papatya çaylarında \% 95 olarak bulunmuştur.

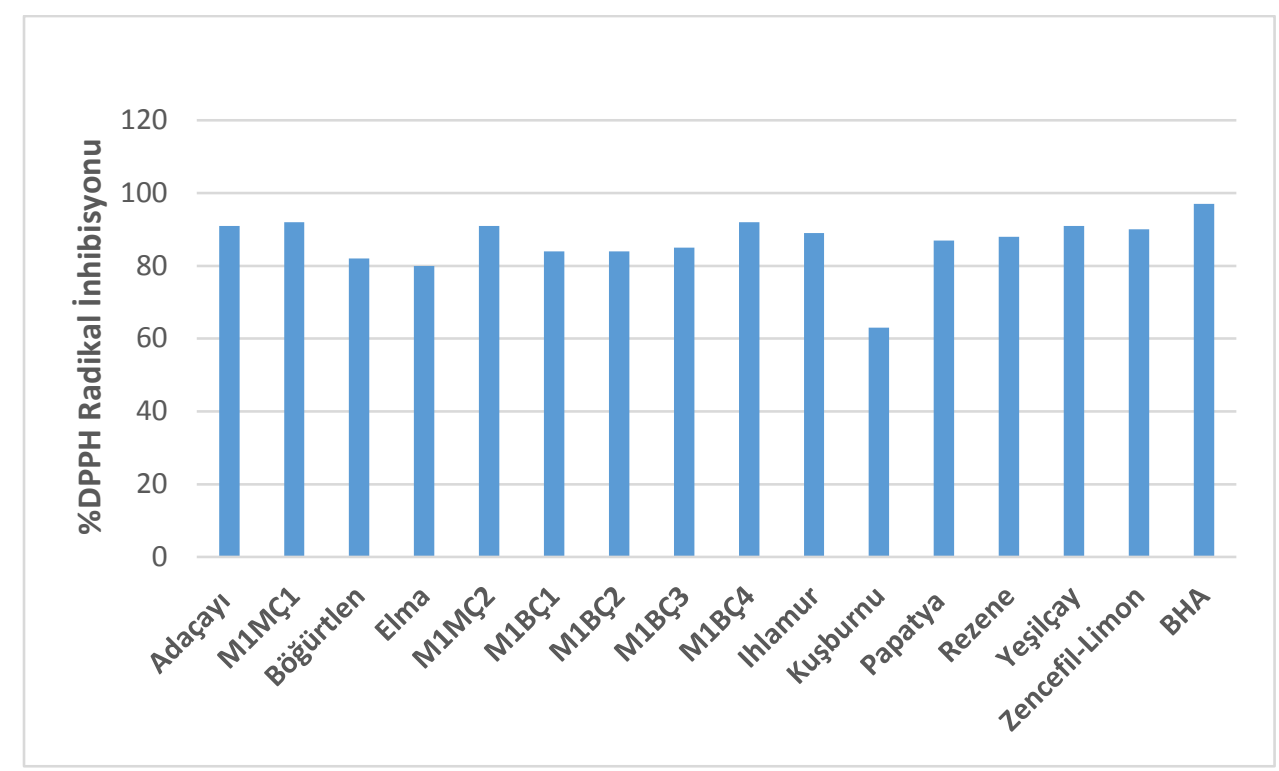

Şekil 1. Marka 1'in \% DPPH radikal inhibisyonu 


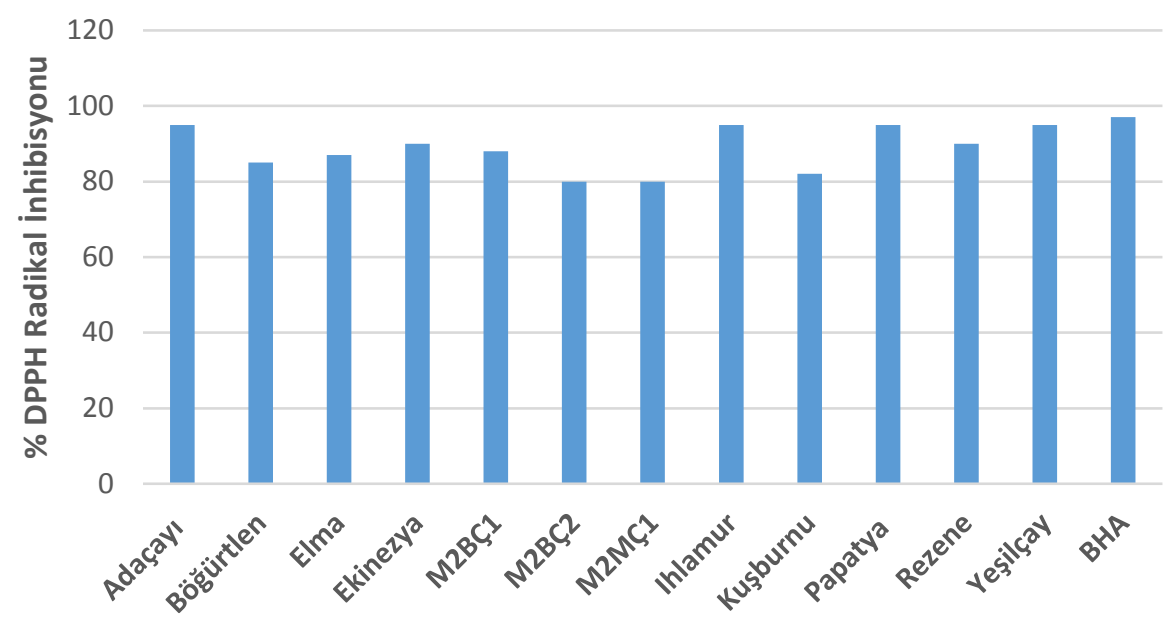

Şekil 2. Marka 2’nin \% DPPH radikal inhibisyonu

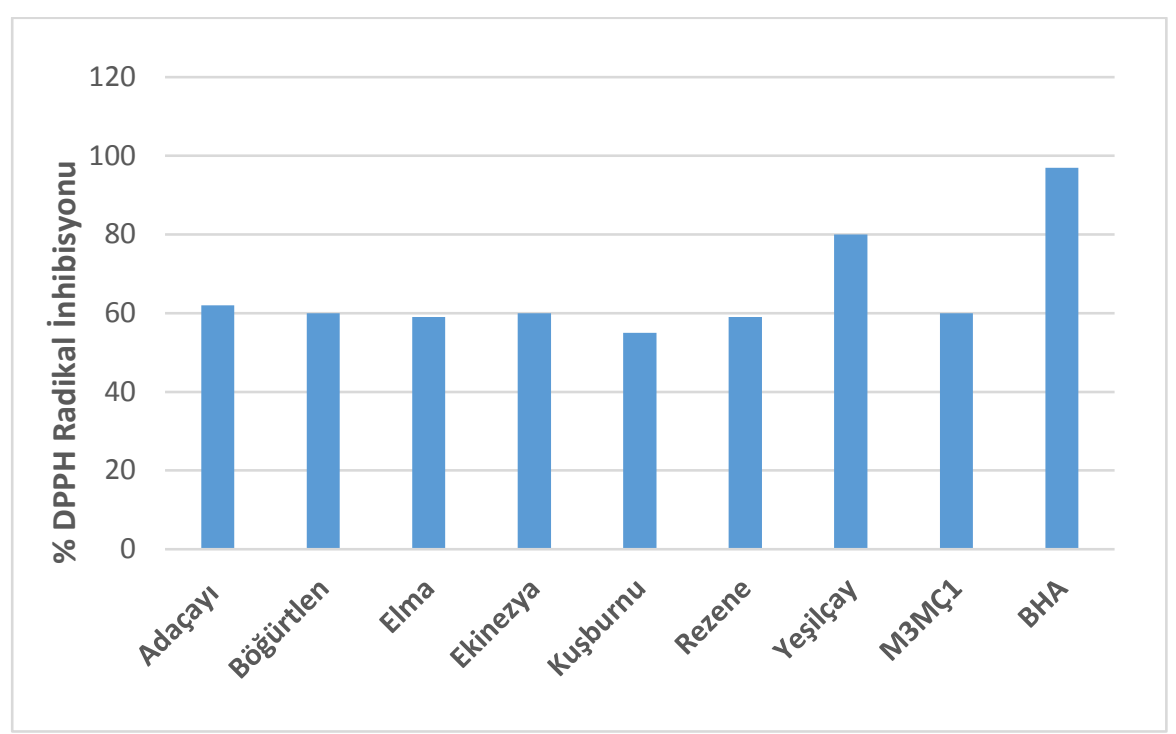

Şekil 3. Marka 3'ün \% DPPH radikal inhibisyonu

Marka 3'te en yüksek DPPH radikal inhibisyonunu \% 80 oranıyla yeşilçay gösterirken en düşük değer \% 55 oranıyla kuşburnu çayı için bulunmuştur. Adaçayının değeri ise \% 62 olarak belirlenmiştir. Adaçayının antioksidan özelliği içerdiği rosmarinik asit ve karnosik asitle ilişkilendirilmektedir (Cuvelier ve ark., 1994). Analizi yapılan tüm markalara ait çayların \% DPPH radikal inhibisyonu sonuçları standart olarak kullanılan BHA'dan düşük bulunmuştur. Analizi yapılan tüm çay örneklerinde önemli ölçüde antioksidan aktivite bulunmuştur. Bulunan bu sonuçlar antioksidan aktivitenin sadece fenolik bileşenlerden değil bunun yanı sıra bitkilerde bulunan diğer biyoaktif bileşenlerden de kaynaklanabileceğini göstermektedir. Çaylarla ilgili yapılan bir araştırmada en yüksek antioksidan aktivite adaçayı için bulunmuştur (Ağagündüz, 2020). YüceDursun (2017) çalışmasında ise en yüksek antioksidan aktiviteyi yeşil çay için bulmuştur. Bu sonuçlar 
çalışmamızla benzerlik göstermektedir. Poşet çayların kullanımı pratik olduğundan günümüzde popülaritesi giderek artmaktadır. Bu nedenle bu çayların yüksek antioksidan kapasiteye sahip olmaları tüketimlerinin insan sağlığına da olumlu etkileri olduğunu gösterir.

\subsection{2. İndirgeme Gücü Antioksidan Kapasitesi Tayini}

İndirgeme gücü denemesi fenolik bileşenlerin elektron verebilme kapasitesinin bir ölçüsüdür. Buna göre antioksidan aktivite belirlenmektedir. Bu metot da ortamdaki indirgen madde $\mathrm{Fe}^{3+}$ iyonlarını $\mathrm{Fe}^{2+}$ iyonlarına indirger ve $\mathrm{FeCl}_{3}$ ilavesiyle oluşan Prusya mavisi rengindeki kompleksin absorbansı ölçülür. Yüksek absorbans değeri yüksek indirgeme gücü kapasitesinin göstergesidir.

Tablo 6. Marka 1, Marka 2 ve Marka 3’ün İndirgeme gücü sonuçları

\begin{tabular}{|c|c|c|c|}
\hline \multirow[b]{2}{*}{ Örnek Adı } & \multicolumn{3}{|c|}{$\mathrm{ABS}_{700 \mathrm{~nm}}$} \\
\hline & Marka 1 & Marka 2 & Marka 3 \\
\hline Adaçayı & 0.409 & 0.354 & 0.413 \\
\hline M1MÇ1 & 0.422 & - & - \\
\hline Böğürtlen & 0.387 & 0.400 & 0.388 \\
\hline Elma & 0.366 & 0.442 & 0.377 \\
\hline Ekinezya & - & 0.437 & 0.388 \\
\hline M1MÇ2 & 0.413 & - & - \\
\hline M1BÇ1 & 0.383 & - & - \\
\hline M1BÇ2 & 0.413 & - & - \\
\hline M1BÇ3 & 0.382 & - & - \\
\hline M2BÇ1 & - & 0.323 & - \\
\hline M1BÇ4 & 0.418 & - & - \\
\hline Ihlamur & 0.354 & 0.267 & \\
\hline Kuşburnu & 0.437 & 0.427 & 0.456 \\
\hline M2MÇ1 & - & 0.374 & - \\
\hline M2BÇ2 & - & 0.391 & - \\
\hline Papatya & 0.287 & 0.334 & \\
\hline Rezene & 0.362 & 0.342 & 0.327 \\
\hline M3MÇ1 & - & - & 0.394 \\
\hline Yeşilçay & 0.437 & 0.409 & 0.441 \\
\hline Zencefil Limon & 0.354 & - & - \\
\hline
\end{tabular}

Not: - ile gösterilen sütunlardaki çay belirtilen markada üretilmemektedir. Bu nedenle analizi yapılamamıştır. 
Tüm markalara ait çayların indirgeme gücü sonuçları Tablo 6'da görülmektedir. Marka 1'in indirgeme gücü değeri en düşük papatya çayında 0.287 , en yüksek ise kuşburnu çayında 0.437 olarak belirlenmiştir. Marka 2'nin indirgeme gücü değerleri 0.267-0.442 aralığında ölçülmüştür. Ihlamur çayı en düşük, elma çayı ise en yüksek değeri göstermiştir. Marka 3’ün indirgeme gücü değerleri diğer markalardan yüksek olarak 0.327-0.456 aralığında sırasıyla rezene ve kuşburnu çaylarında bulunmuştur.

\section{4. İstatistiksel Analizler}

Marka 1,2 ve 3'ün DPPH, toplam fenolik, toplam flavonoid ve indirgeme gücü değerleri arasındaki korelasyon Tablo 7'de gösterilmiştir. Marka 1'in DPPH ve toplam fenolik değerleri arasında korelasyon bulunamamıştır(p>0.05). DPPH ve toplam flavonoid değerleri arasında orta şiddette korelasyon $(\mathrm{r}=0.567)$ bulunurken, indirgeme gücü ile toplam fenolik değerleri arasında çok yüksek korelasyon ( $\mathrm{r}=0.899)$, indirgeme gücü ile flavonoid içeriği arasında yüksek korelasyon $(\mathrm{r}=0.729)$ olduğu tespit edilmiştir.

Marka 2'nin DPPH değerleri toplam fenolik, toplam flavonoid ve indirgeme gücü değerleri ile korelasyon göstermezken ( $\mathrm{p}>0.05)$, toplam fenolik ve flavonoid değerleri arasında çok yüksek korelasyon bulunmuştur ( $\mathrm{r}=0.907)$. Toplam fenolik bileşen içeriğinin antioksidan aktiviteye katkısı yüksek olmakla birlikte bitkilerde bulunan karotenoid, vitamin ve uçucu yağların da önemli ölçüde etkisi olmaktadır (Şahin, 2013).

Marka 3'ün indirgeme gücü ve fenolik değerleri arasında yüksek korelasyon ( $\mathrm{r}=0.755)$, fenolik ve flavonoid değerleri arasında çok yüksek korelasyon ( $r=0.929)$ olduğu tespit edilmiştir.

Tablo 7. Marka 1,2,3'e ait poşet çayların toplam fenolik, flavonoid, \% DPPH ve indirgeme gücü değerleri korelasyonu

$\begin{array}{ccccc}\text { DPPH } & \text { DPPH } & \text { Toplam } & \text { İndirgeme } & \text { İndirgeme } \\ \text { Toplam Fenolik } & \text { Toplam Flavonoid } & \text { Fenolik } & \text { Gücü } & \text { Gücü } \\ & & \text { Toplam Flavonoid } & \text { Toplam Fenolik } & \text { Toplam Flavonoid }\end{array}$

\begin{tabular}{llllll}
\hline $\begin{array}{c}\text { Marka } \\
1\end{array}$ & $/$ & $/$ & 0.567 & 0.899 & 0.729 \\
\hline Marka & $/$ & & & $/$ \\
2 & $/$ & 0.907 & $/$ & $/$ \\
\hline Marka & $/$ & $/$ & 0.929 & 0.755 & $/$ \\
\hline
\end{tabular}


Bizim sonuçlarımıza benzer şekilde çeşitli bitki ekstrelerinin toplam fenolik bileşen içeriği ile antioksidan aktivitesi arasında korelasyon bulunamadığı literatürde bildirilmiştir (Kähkönen ve ark., 1999). Yine başka bir çalışmada flavonoid bileşen içeriği ve DPPH radikal inhibisyonu arasında düşük korelasyon bulunduğu bildirilmiş ve bunun flavonoidlerin hidrojen verme kapasiteleri alakalı olabileceği belirtilmiştir (Miliauskas ve ark., 2004). Bunun aksine başka bir çalışmada toplam fenolik bileşen içeriği ile indirgeme gücü arasında yüksek korelasyon olduğu belirtilmiştir (Hassas-Roudsari ve ark., 2009).

\section{Sonuçlar ve Öneriler}

$\mathrm{Bu}$ çalışmada marketlerde satılan günlük hayatlarımızda sıklıkla tükettiğimiz poşet çayların fenolik, flavonoid bileşen içeriği ve antioksidan aktivitesi araştırılmış ve birbirleriyle kıyaslanmıştır. Literatürde de yüksek antioksidan aktivite gösterdiği bildirilen adaçayı ve yeşil çayların poşet çaylarının da önemli ölçüde antioksidan aktiviteye sahip olduğu bulundu. Papatya, rezene, 1hlamur ve bunun yanı sıra çeşitli bitki-meyve karışımlarından oluşan poşet çayların fenolik ve flavonoid içerikleri düşük bulundu. Adaçayı ve karışım çayların radikal giderme aktiviteleri diğer çaylara göre yüksek bulundu. Marketlerde satılan bitki-meyve poşet çayları referans olarak kullanılan BHA ile kıyaslandığında önemli ölçüde antioksidan aktiviteye sahip olduğu bulundu. Çalışmamızda Türkiye' de marketlerde satılan farklı markalara ait toplam 36 farklı bitki-meyve çayı örneklerinde ilk defa bu kadar kapsamlı bir fenolik, flavonoid ve antioksidan çalışması yapılmıştır. İleriki çalışmalarla çaylarda bulunan biyoaktif bileşen profilleri analiz edilip bu sayede antioksidan aktiviteye sebep olan bileşenler belirlenebilir. İçerdikleri yüksek antioksidan aktiviteleri nedeniyle bitki ve meyve çaylarının kullanımının sağlık üzerine olumlu etkileri olduğu söylenebilir.

\section{Yazarların Katkısı}

Zeynep Kübra Menekşe deneysel kısımda, Burcu Marangoz istatistiksel verilerin değerlendirilmesi ve yazılması kısmında, Sibel Kahraman yayının deneysel tasarlama kısmında ve yazılmasında çalışmaya katkıda bulunmuştur.

\section{Çıkar Çatışması Beyanı}

Yazarlar arasında herhangi bir çıkar çatışması bulunmamaktadır. 


\section{Araştırma ve Yayın Etiği Beyanı}

Yapılan çalışmada araştırma ve yayın etiğine uyulmuştur.

\section{Kaynaklar}

Ağagündüz D., (2020). Organik Çay İnfüzyonlarının Toplam Antioksidan ve Oksidan Kapasitelerinin Değerlendirilmesi, Beslenme ve Diyet Dergisi, 48(2), 5-1.

Akgun, A., Unver, A., (2001). Bitkisel çaylar. Gıda Mühendisliği Dergisi. 11 Aralık, 21-24.

Brand-Williams, W., Cuvelier, M., Berset, C., (1995). Use of a free radical method to evaluate antioxidant activity. LWT-Food Science and Technology, 28, 25-30.

Cavlak, S., Yağmur, C., (2016). Bazı poşet çaylarin toplam fenolik madde ve antioksidan aktivitelerinin belirlenmesi. Ç.Ü. Fen ve Mühendislik Bilimleri Dergisi, 34(4), 11-9.

Cuvelier, M. E., Berset, C., Richard H.,(1994). Journal of Agricultural Food Chemistry, 42 (3), 665669.

Hassas-Roudsari, M., Chang, P. R., Pegg, R. B., \& Tyler, R. T., (2009). Antioxidant capacity of bioactives extracted from canola meal by subcritical water, ethanolic and hot water extraction. Food Chemistry, 114(2), 717-726.

Kähkönen, M. P., Hopia, A. I., Vuorela, H. J., Rauha, J.-P., Pihlaja, K., Kujala, T. S., \& Heinonen, M., (1999). Antioxidant Activity of Plant Extracts Containing Phenolic Compounds. Journal of Agricultural and Food Chemistry, 47, 3954-3962.

Miliauskas, G., Venskutonis, P. R., \& Van Beek, T. A., (2004). Screening of radical scavenging activity of some medicinal and aromatic plant extracts. Food Chemistry, 85(2), 231-237.

Oyaizu, M., (1986). Studies on Products of Browning Reactions: Antioxidative Activities of Product of Browning Reaction Prepared from Glucosamine. Japan Journal of Nutrition, 44, 307-315.

Piljac-Žegarac, J., Valek, L., Stipčević, T. \& Martinez, S., (2010). Electrochemical determination of antioxidant capacity of fruit tea infusions. Food Chemistry, 121, 820825.

Pérez-Ramírez, I. F., Castaño-Tostado, E., Ramírez-De León, J. A., Rocha-Guzmán, N. E., \& ReynosoCamacho, R., (2015). Effect of stevia and citric acid on the stability of phenolic compounds and in vitro antioxidant and antidiabetic capacity of a roselle (Hibiscus sabdariffa L.) beverage. Food Chemistry, $172,885-892$.

Shahidi, F., Naczk, M., (1995). Food Phenolics, Chemistry, Effects, Applications: Technomic Publishing Co, Lancaster, USA.

Siatka, T., \& Kašparová, M., (2010). Seasonal variation in total phenolic and flavonoid contents and DPPH scavenging activity of Bellis perennis L. flowers. Molecules, 15(12), 9450-9461.

Singleton, V. L. and Rossi, J. A., Jr., (1965). Colorimetry of total phenolics with phosphomolybdicphosphotungstic acid reagents. American Journal of Enology and Viticulture, 16,144-158.

Sahin, S., (2013). Evaluation of antioxidant properties and phenolic composition of fruit tea infusions. Antioxidants, 2, 206-215.

Yüce-Dursun, B., (2017). Çeşitli bitki çaylarının monoamin oksidaz inhibisyonlarının ve antioksidan etkilerinin belirlenmesi. Trakya University Journal of Natural Sciences, 18(2), 105-113.

Zhishen, J., Mengcheng, T., Jianming, W., (1999). Research on antioxidant activity of flavonoids from natural materials, Food Chemistry, 64, 555-559. 